\title{
Determination of T1D-Susceptible HLA DR-DQ Haplotypes in Yakuts Using Three Single Nucleotide Polymorphisms
}

\author{
Nadezhda I. Pavlova, $\mathrm{PhD}^{1^{*}}$; Khariton A. Kurtanov, $\mathrm{PhD}^{1}$; Natalia A. Solovyeva, $\mathrm{PhD}^{1}$; \\ Aleksandra T. Diakonova ${ }^{1}$; Ljubov' Ah. Sydykova, $\mathrm{PhD}^{2,3}$; Tuiara N. Aleksandrova ${ }^{1}$; \\ Yulia A. Solovyeva ${ }^{1}$; Vladimir V. Dodohov, $\mathrm{PhD}^{1,4}$ \\ ${ }^{1}$ Yakut Science Center of Complex Medical Problems; ${ }^{2}$ M. K. Ammosov North-Eastern Federal University \\ ${ }^{3}$ Yakut Republican Clinical Hospital; ${ }^{4}$ Yakut State Agricultural Academy \\ Yakutsk, the Republic of Sakha (Yakutia), Russia
}

\begin{abstract}
The purpose of this study was to determine T1D-susceptible HLA DR-DQ haplotypes in Yakuts using 3 single nucleotide polymorphisms (rs3104413C/G, rs2854275G/T and rs9273363A/C). A total of 92 patients with a verified diagnosis of T1D (Group 1) were examined. The comparison group consisted of 210 people (Group 2) without autoimmune diseases and without hereditary predisposition. All participants were Yakuts by ethnicity.

According to the results of genotyping, it was established that the haplotype $D R B 1 * 03: 01-D Q A 1 * 05: 01-D Q B 1 * 02: 01$ corresponds to the rs3104413C/C-rs2854275T/T combination and the rs3104413C/G-rs2854275G/T-rs9273363C/C combination. DRB1*04:01$D Q A 1 * 03: 01-D Q B 1 * 03: 02$ haplotype (DR4-DQ8) is the rs3104413G/G-rs9273363A/C combination, the rs3104413C/G-rs2854275G/ G-rs9273363A/C combination, and the rs3104413C/G-rs2854275G/G-rs9273363A/A combination. DR3/4-DQ8 haplotype is the rs3104413C/G-rs2854275G/T-rs9273363A/A combination and the rs3104413C/G-rs2854275G/T-rs9273363A/C combination. $D R B 1 * 04: 01-D Q A 1 * 03: 01-D Q B 1 * 03: 01$ haplotype is the rs3104413G/G-rs9273363C/C combination, the rs3104413C/G-rs2854275G/ G-rs9273363C/C combination, and the rs3104413C/G-rs2854275G/T-rs9273363C/C combination. A combination of rs3104413C/C with rs $2854275 \mathrm{G} / \mathrm{G}$ was characterized by the absence of DR3 and DR4, which may be due to the presence of a different genetic variant in these individuals. A combination of rs $3104413 \mathrm{C} / \mathrm{C}$ with $\mathrm{rs} 2854275 \mathrm{G} / \mathrm{T}$ was characterized by the presence of only one type of DR3 and a variant of the type that does not belong to either DR3 or DR4. An analysis of the evaluation of the effectiveness of a diagnostic test using the Youden index demonstrated significance for all combinations of genotypes of the studied polymorphisms. (International Journal of Biomedicine. 2019;9(3):216-219.)
\end{abstract}

Key Words: haplotype $\bullet$ single nucleotide polymorphism $•$ Yakuts $\bullet$ type 1 diabetes

\section{Introduction}

Type 1 diabetes(T1D), a multifactorial disease with astrong genetic component, is caused by the autoimmune destruction of pancreatic $\beta$ cells. ${ }^{(1,2)}$ The major T1D susceptibility locus maps to the class II loci $H L A-D R B 1$ and $H L A-D Q B 1$ on chromosome 6p21. The DR-DQ haplotypes conferring the highest risk are $D R B 1 * 03: 01-D Q A 1 * 05: 01-D Q B 1 * 02: 01 \quad$ (abbreviated "DR3") and DRB1*04:01/02/04/05/08-DQA1*03:01-

*Corresponding author: Nadezhda I. Pavlova, PhD. Yakut Science Center of Complex Medical Problems. Yakutsk, the Republic of Sakha (Yakutia), Russia.E-mail: solnishko_84@inbox.ru
$D Q B 1 * 03: 02 / 04$ (or $D Q B 1 * 02$; abbreviated "DR4"). (3) More than $80 \%$ of T1D patients are carriers of one or both haplotypes. It is important that the polymorphism of HLA genes can also have a pronounced protective effect. ${ }^{(4,5)}$ HLA genes can also have an impact on the clinical features of the disease, such as the age of onset or the outcome of active cellular autoimmunity. Therefore, the haplotype $D R B 1 * 03: 01-D R B 1 * 04: 01(\mathrm{DR} 3 / 4)$ not only strongly predisposes to the development of T1D, but also accelerates the onset of the disease (i.e. occurs much more frequently among patients with the onset of T1D in early childhood). ${ }^{(6)}$ In the Russian population, high-risk genotypes (DQ2/DQ8) were significantly more common in children who were sick before the age of $5(33 \%)$, compared 
with children in whom T1D manifested at the age of 10 years $(23 \%){ }^{(7)}$ The results obtained in Yakutia will be in demand in the development of a personalized approach to diagnosis (screening) and prevention of T1D.

The purpose of this study was to determine T1Dsusceptible HLA DR-DQ haplotypes in Yakuts using 3 single nucleotide polymorphisms (rs3104413C/G, rs2854275G/T and rs9273363A/C).

\section{Materials and Methods}

The study was approved by the Ethics Committee of the Yakut Science Center of Complex Medical Problems (YSC CMP). The HLA-DR/DQ genotyping was performed in the laboratory of molecular genetics at YSC CMP. A total of 92 patients with a verified diagnosis of T1D (Group 1) were examined. The comparison group consisted of 210 people (Group 2) without autoimmune diseases and without hereditary predisposition. All participants were Yakuts by ethnicity. The ethnic origin was considered to the third generation. The study was performed after participants signed a written, informed consent; for participants under the age of adulthood, the informed consent was signed by parents. For each study participant, an individual genetic map was developed, containing clinical, functional and laboratory parameters, as well as genealogical data of the participant. Relatives were excluded from the analysis.

Genomic DNA samples were isolated from the peripheral blood leukocytes using a commercial DNA kit, Excel biotech (Yakutsk). Studies of HLA-DR and HLA-DQ gene variants were carried out using an allele-specific PCR (AS-PCR), according to Cao Nguyen (2013) ${ }^{(8)}$ Characteristics of single-nucleotide polymorphisms rs3104413, rs2854275, rs9273363 are presented in Table 1. SNP selection was based on a study conducted by Cao Nguyen and colleagues, who analyzed 19,035 SNPs of 10,579 subjects (7,405 from a discovery set and 3,174 from a validation set) from the Type 1 Diabetes Genetics Consortium and developed a novel machine learning method to select as few as 3 SNPs that could define the HLA-DR and HLA-DQ types accurately. Thus, 3 SNPs were proposed to accurately determine the types of HLA-DR and HLA-DQ. The high accuracy is consistent with the proximity of the SNPs to the class II genes (rs3104413 is located in the intergenic region between $H L A-D R B 1$ and $H L A-D Q A 1$, rs 2854275 is within the $H L A-D Q B 1$ gene, and rs9273363 is in close proximity to the $H L A-D Q B 1$ gene) and with the strong linkage disequilibrium between HLA genes. ${ }^{(8)}$

Table 1.

Characteristics of single-nucleotide polymorphisms rs3104413, rs2854275, rs9273363

\begin{tabular}{|c|c|c|c|c|c|}
\hline Gene & SNP & $\begin{array}{c}\text { Localization } \\
\text { (hg19) }\end{array}$ & Allele & Method & MAF \\
\hline$H L A-D Q A 1$ & rs3104413 & chr6: 32582650 & C/G & RT-PCR & $0.13(\mathrm{G})$ \\
\hline$H L A-D Q B 1$ & rs2854275 & chr6: 32660651 & G/T & AS-PCR & $0.06(\mathrm{~T})$ \\
\hline$H L A-D Q B 1$ & rs9273363 & chr6: 32658495 & A/C & AS-PCR & $0.24(\mathrm{~A})$ \\
\hline
\end{tabular}

$M A F$ is the minor allele frequency; hg19 is the reference genome
At the first stage, for definition of HLA-DR types, rs3104413 SNP was used. Further research tactics were determined depending on the genotype established at the first stage. Thus, individuals homozygous for rs3104413C (C/C) were further investigated by rs 2854275 , homozygous for rs3104413G $(\mathrm{G} / \mathrm{G})$ by rs9273363, and $\mathrm{C} / \mathrm{G}$ heterozygous for rs3104413 $(\mathrm{C} / \mathrm{G})$ were investigated for both SNPs.

To determine compliance with the HLA-DR and HLADQ haplotypes with the studied SNPs (rs3104413, rs2854275, and rs9273363), a commercial HLA-Type kit (BAG Health Care $\mathrm{GmbH}$, Germany) was used. The genotyping of HLADRB1 and DQB1 alleles was carried out according to previously described methods. ${ }^{(9,10)}$ Haplotype combinations of the three analyzed polymorphisms were used for defining the HLA types relevant to T1D (Nguyen et al, 2013) ${ }^{\left({ }^{(8)}\right.}$ distinguishing the highest-risk DR4- DQ8 and DR3/4-DQ types.

Statistical analysis was performed using the Statistica 8.0 software package (StatSoft Inc, USA).The frequencies of the alleles and genotypes of SNPs (rs3104413, rs2854275, and rs9273363) were determined by direct counting, using generally accepted formulas. To determine the effectiveness of the diagnostic test, the Youden index was calculated using the following formula: $\mathrm{J}=\mathrm{Sen}+\mathrm{Spe}-1$,

$\mathrm{J}$ - the Youden index, Sen - sensitivity, Sp -specificity

Indicators Sen and Spe were calculated using the following formulas: $\mathrm{Sen}=\mathrm{TP} /(\mathrm{TP}+\mathrm{FN})$ and $\mathrm{Spe}=\mathrm{TN} /(\mathrm{TN}+\mathrm{FP})$,

TP-true positive value, $\mathrm{FP}$ - false positive value, $\mathrm{TN}-$ true negative value, $\mathrm{FN}$ - false negative value.

\section{Results and Discussion}

Depending on the distribution of genotypes of the investigated polymorphisms, in patients of Group 1 with rs3104413C/C, rs2854275G/T prevailed, which corresponds to the HLA DR3/X genotype. rs2854275T/T associated with adverse haplotype $D R B 1 * 03-D Q A 1 * 05: 01-D Q B 1 * 02: 01$ was found in $21.9 \%$ of cases in this group. Patients with rs $2854275 \mathrm{G} / \mathrm{G}(12.5 \%)$ were characterized by the absence of DR3 and DR4, which may be due to the presence in these individuals of another allelic variant (Table 2).

Among patients with $\mathrm{rs} 3104413 \mathrm{C} / \mathrm{G}, \quad 50 \%$ had rs2854275G/T, associated with haplotypes $D R B 1 * 03$ $D Q A 1 * 05: 01-D Q B 1 * 02: 01$ and DR3/4-DQ8, and 50\% had rs2854275G/G, associated with haplotype DR4/4-DQ8.

Among patients with rs $3104413 \mathrm{G} / \mathrm{G}, \mathrm{rs} 9273363 \mathrm{~A} / \mathrm{C}$ associated with the DR4-DQ8 haplotype was found in 100\% of cases. Among patients with rs $3104413 \mathrm{C} / \mathrm{G}$, rs $9273363 \mathrm{~A} / \mathrm{C}$ was prevalent, which in $37.5 \%$ of cases correspondents to DR4-DQ8 and in 25\% - DR3/4-DQ8.

The results of the distribution of HLA gene alleles among T1D patients are consistent with the results of E.V. Titovich (2009). ${ }^{(5)}$ In a comparative analysis of the predisposing alleles distribution frequencies among the Yakut population and the Russian population of Moscow, it was shown that among T1D patients in the Yakut population, alleles of $D R B 1 * 04$ (DR4) and $D R B 1^{*} 17(03)$ are more common. The authors also showed that $D R B 1^{*} 17(03)$ is the most predisposing allele in the Yakut population. 
Table 2.

Distribution of haplotypes in the group of patients with T1D depending on the distribution of SNP genotypes

\begin{tabular}{|c|c|c|c|c|c|c|c|c|c|c|c|c|c|c|c|}
\hline SNP & \multicolumn{15}{|c|}{$\mathrm{rs} 3104413, \mathrm{n}=92$} \\
\hline $\begin{array}{l}\text { Genotype, } \\
\text { n (\%) }\end{array}$ & \multicolumn{3}{|c|}{$\mathrm{C} / \mathrm{C} \quad 64$ (69.6) } & \multicolumn{9}{|c|}{$\mathrm{C} / \mathrm{G} \quad 16(17.4)$} & \multirow{2}{*}{\multicolumn{3}{|c|}{$\begin{array}{c}\mathrm{G} / \mathrm{G} \quad 12(13.0) \\
\mathrm{rs} 9273363\end{array}$}} \\
\hline SNP & \multicolumn{3}{|c|}{ rs 2854275} & \multicolumn{4}{|c|}{ rs 2854275} & \multicolumn{5}{|c|}{ rs9273363 } & & & \\
\hline Genotype & $\mathrm{T} / \mathrm{T}$ & $\mathrm{G} / \mathrm{T}$ & $\mathrm{G} / \mathrm{G}$ & $\mathrm{G} / \mathrm{T}$ & & $\mathrm{G} / \mathrm{G}$ & $\mathrm{T} / \mathrm{T}$ & & $/ \mathrm{A}$ & $\mathrm{A} / \mathrm{C}$ & & $\mathrm{C} / \mathrm{C}$ & $\mathrm{A} / \mathrm{A}$ & $\mathrm{A} / \mathrm{C}$ & $\mathrm{C} / \mathrm{C}$ \\
\hline $\mathrm{n}(\%)$ & $14(21.9)$ & $42(65.6)$ & $8(12.5)$ & $2(12.5)^{* *}$ & $6(37.5)$ & $8(50)$ & 0 & $2(12.5)$ & $2(12.5)$ & $6(37.5)^{* * * *}$ & $4(25)$ & $2(12.5)$ & 0 & $12(100)$ & 0 \\
\hline \begin{tabular}{|l|} 
Haplotypes \\
obtained \\
with \\
Histotype \\
Kit
\end{tabular} & $\begin{array}{l}D R B 1 * 03- \\
D Q A 1 * 05: 01- \\
D Q B 1 * 02: 01\end{array}$ & $\mathrm{DR} 3 / \mathrm{X}$ & $\mathrm{DRX} / \mathrm{X}$ & $\begin{array}{l}D R B 1^{*} 03- \\
D Q A 1 * 05: 01- \\
D Q B 1 * 02: 01\end{array}$ & \begin{tabular}{|l|} 
DR3/4- \\
DQ8
\end{tabular} & - lDR4- & - & $\begin{array}{l}\text { DR3/4- } \\
\text { DQ8 }\end{array}$ & 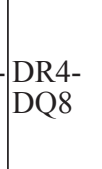 & \begin{tabular}{|l} 
DR4- \\
DQ8
\end{tabular} & \begin{tabular}{|l} 
DR3/4- \\
DQ8
\end{tabular} & $\begin{array}{l}D R B 1 * 03- \\
D Q A 1^{*} 05: 01- \\
D Q B 1 * 02: 01\end{array}$ & -1 & $\begin{array}{l}\text { DR4- } \\
\text { DQ8 }\end{array}$ & - \\
\hline
\end{tabular}

$D R / X$ - lack of DR3 and DR4; DR3/X - variant carriers of one type DR3 and a type without relation to DR3 and DR4

** - carriers of rs $9273363 C / C$ and rs $2854275 G / T$; *** - carriers of $r s 2854275 G / G$ and $r s 9273363 A / C$

Table 3.

Distribution of haplotypes in the control group depending on the distribution of SNP genotypes

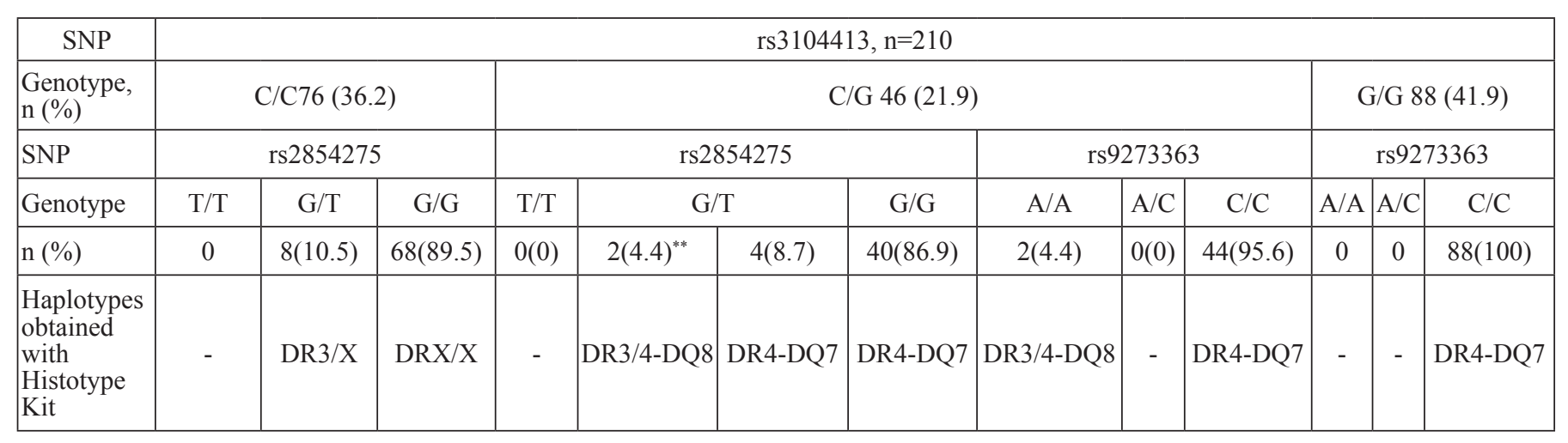

$D R / X$ - lack of DR3 and DR4; DR3/X - variant carriers of one type DR3 and a type without relation to DR3 and DR4

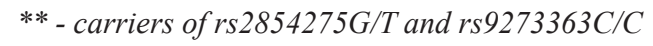

Table 4.

Identification of HLA haplotypes and genotypes using SNPS (rs3104413, rs2854275, rs9273363)

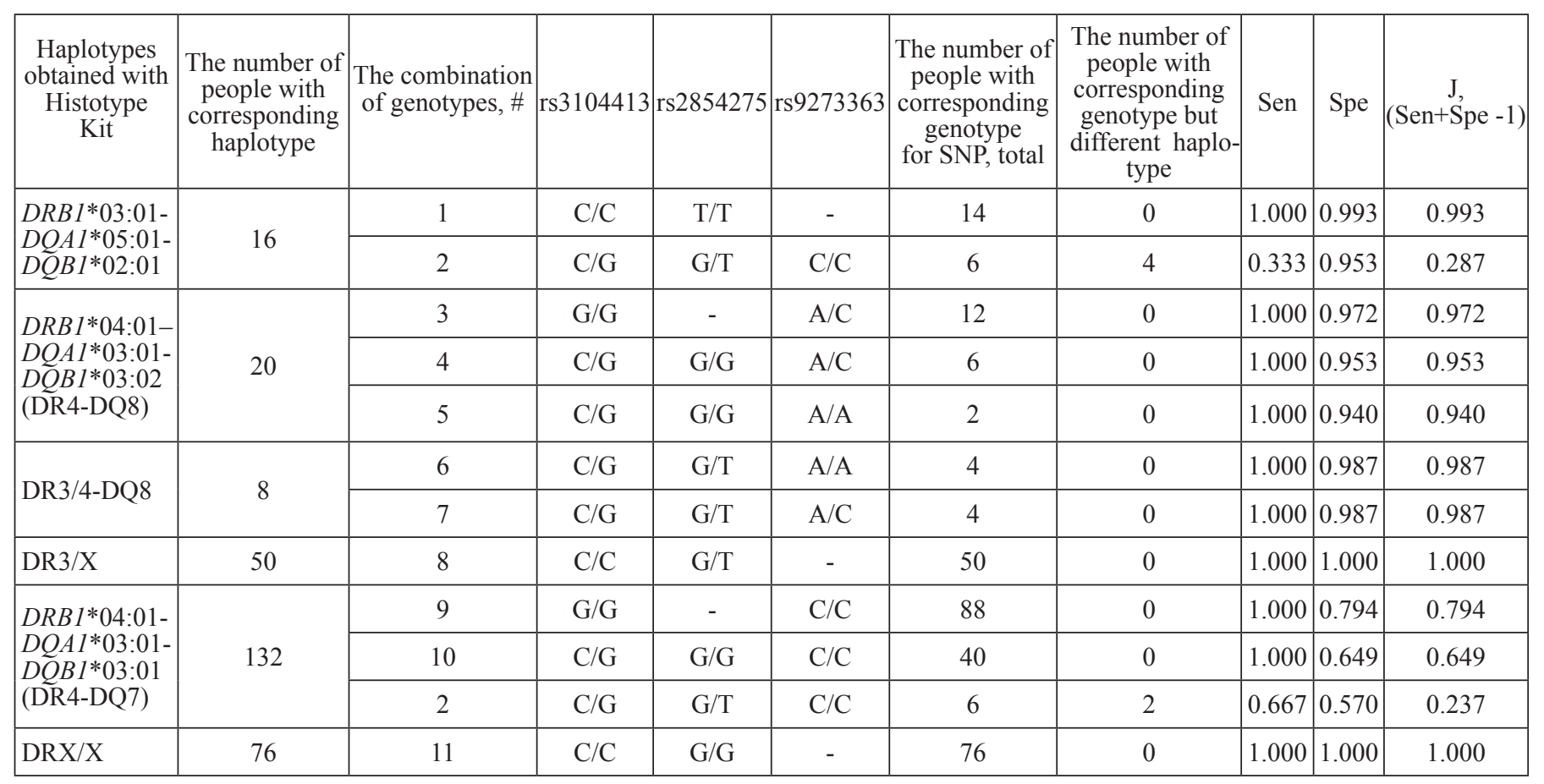


Analysis of haplotype distribution in Group 2 demonstrated the following results: in carriers of $\mathrm{rs} 3104413 \mathrm{C} / \mathrm{G}$, the vast majority of individuals had $\mathrm{rs} 2854275 \mathrm{G} / \mathrm{G}$ associated with the low-risk genotype DR4-DQ7. ${ }^{(8)}$ Evaluation of rs9273363 SNP among individuals with rs3104413G/G and rs310441C/G demonstrated the prevalence of $\mathrm{rs} 9273363 \mathrm{C} / \mathrm{C}$ associated with the DR4-DQ7 genotype, rs9273363A/C was completely absent (Table 3 ).

In order to determine the sensitivity and specificity of rs3104413, rs2854275, and rs9273363 with respect to HLA haplotypes and genotypes, the Youden index was evaluated (Table 4). For most of the analyzed combinations of genotypes of the studied polymorphisms, the Youden index varied significantly from 0.649 to 1 , with the exception of option \#2. The highest value of the Youden index for the genotype DR3/X was established for combinations \#8 and the lack of a carrier state of DR3 and DR4 - combination \#11 (Table 4).

\section{Conclusion}

According to the results of genotyping, it was established that the haplotype $D R B 1 * 03: 01-D Q A 1 * 05: 01-D Q B 1 * 02: 01$ corresponds to the rs $3104413 \mathrm{C} / \mathrm{C}$-rs $2854275 \mathrm{~T} / \mathrm{T}$ combination and the rs3104413C/G-rs2854275G/T-rs9273363C/C combination.

The haplotype $D R B 1 * 04: 01-D Q A 1 * 03: 01-D Q B 1 * 03: 02$ (DR4-DQ8) is the rs3104413G/G-rs9273363A/C combination, the rs3104413C/G-rs2854275G/G-rs9273363A/C combination, and the rs3104413C/G-rs2854275G/G-rs9273363A/A combination.

DR3/4-DQ8 haplotype is the rs3104413C/G-rs2854275G/Trs9273363A/A combination and the rs3104413C/G-rs2854275G/ T-rs $9273363 \mathrm{~A} / \mathrm{C}$ combination.

$D R B 1 * 04: 01-D Q A 1 * 03: 01-D Q B 1 * 03: 01$ haplotype is the rs3104413G/G-rs9273363C/C combination, the rs3104413C/Grs $2854275 \mathrm{G} / \mathrm{G}-\mathrm{rs} 9273363 \mathrm{C} / \mathrm{C}$ combination, and the rs3104413C/ G-rs2854275G/T-rs9273363C/C combination.

A combination of $\mathrm{rs} 3104413 \mathrm{C} / \mathrm{C}$ with $\mathrm{rs} 2854275 \mathrm{G} / \mathrm{G}$ was characterized by the absence of DR3 and DR4, which may be due to the presence of a different genetic variant in these individuals. A combination of $\mathrm{rs} 3104413 \mathrm{C} / \mathrm{C}$ with rs $2854275 \mathrm{G} / \mathrm{T}$ was characterized by the presence of only one type of DR3 and a variant of the type that does not belong to either DR3 or DR4.

An analysis of the evaluation of the effectiveness of a diagnostic test using the Youden index demonstrated significance for all combinations of genotypes of the studied polymorphisms.

\section{Competing Interests}

The authors declare that they have no competing interests.

\section{Sources of Funding}

The study was supported by the program 'Genome of Yakutia' of the Federal Agency of Scientific Organizations (Grant no. YSC CMP BRK 0556-2017-0003).

\section{References}

1. Steck AK, Rewers MJ. Genetics of type 1 diabetes. Clin Chem. 2011;57(2):176-85. doi: 10.1373/ clinchem.2010.148221.

2. Concannon P, Rich SS, Nepom GT. Genetics of type 1A diabetes. N Engl J Med. 2009 Apr 16;360(16):1646-54. doi: 10.1056/NEJMra0808284.

3. Noble JA, Valdes AM. Genetics of the HLA region in the prediction of type 1 diabetes. Curr Diab Rep. 2011 Dec;11(6):533-42. doi: 10.1007/s11892-011-0223-x.

4. Morran MP, Vonberg A, Khadra A, Pietropaolo M. Immunogenetics of type 1 diabetes mellitus. Mol Aspects Med. 2015;42:42-60. doi:10.1016/j.mam.2014.12.004

5. Titovich EV, Kuraeva TL, Danilova GI, Alekseev LP, Boldyreva MN, Nikitin AN, et al. [Association of type 1 diabetes mellitus (DM1) with polymorphic alleles of HLA class II genes in the Yakutian and Russian populations] Diabetes mellitus. 2009;12(3):26-32. [Article in Russian]. 6. Patterson CC, Dahlquist GG, Gyürüs E, Green A, Soltész G; EURODIAB Study Group. Incidence trends for childhood type 1 diabetes in Europe during 1989-2003 and predicted new cases 2005-20: a multicentre prospective registration study. Lancet. 2009;373(9680):2027-33. doi: 10.1016/S01406736(09)60568-7.

7. Dedov II, Shestakova MV, Kuraeva TL, Titovich EV, Nikonova TV. [Nosological heterogeneity, molecular genetics and immunology of autoimmune diabetes mellitus]. Annals of the Russian Academy of Medical Sciences. 2015;70(2):132138. [Article in Russian].

8. Nguyen C, Varney MD, Harrison LC, Morahan G. Definition of high-risk type 1 diabetes HLA-DR and HLA-DQ types using only three single nucleotide polymorphisms. Diabetes. 2013;62(6):2135-40. doi:10.2337/db12-1398

9. Solov'eva NA, Kurtanov HA, Pavlova NI, D’jakonova AT, Filippova NP, Aleksandrova TN. [Association of DRB1, DQA1, DQB genes of the HLA class II system with the development of type 1 diabetes in the Yakut population]. Modern problems of science and education. 2019;2. URL: http://www.science-education.ru/ru/article/view? id=28721. [Article in Russian].

10. Pavlova NI, Kurtanov HA, D’jakonova AT, Solov'eva NA, Sydykova LA, Aleksandrova TN, et al. [Association of type 1 diabetes mellitus with polymorphic alleles of HLA class II genes in the Yakut population]. Modern problems of science and education. 2019;1. URL: http://www.science-education. $\mathrm{ru} / \mathrm{ru} / \mathrm{article} / \mathrm{view}$ ?id=28568. [Article in Russian]. 